\title{
Bed rest in singleton pregnancies for preventing preterm birth (Review)
}

\author{
Sosa CG, Althabe F, Belizán JM, Bergel E
}

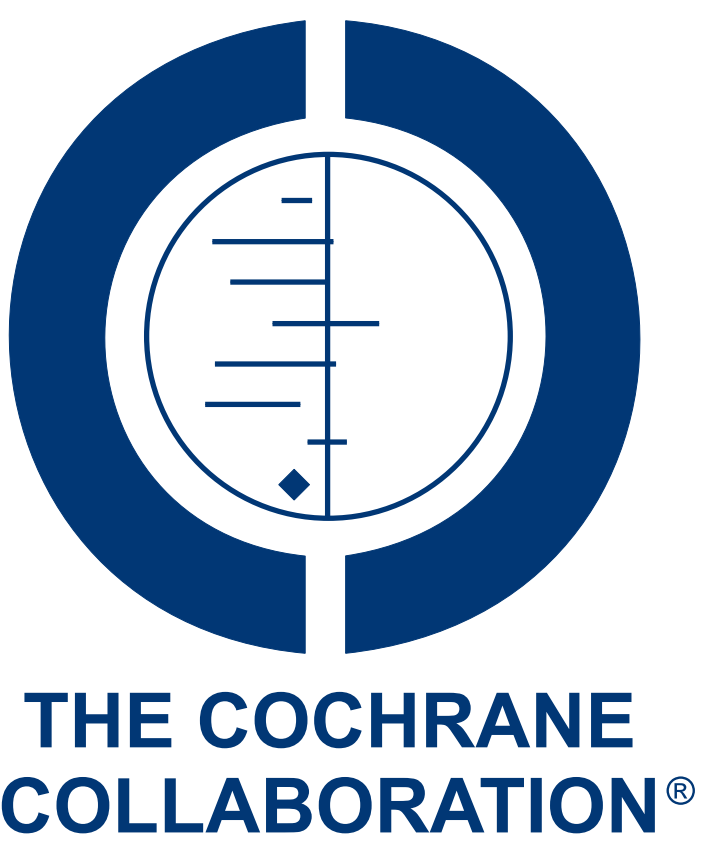

This is a reprint of a Cochrane review, prepared and maintained by The Cochrane Collaboration and published in The Cochrane Library 2015, Issue 3

http://www.thecochranelibrary.com

\section{WILEY}




\title{
[Intervention Review]
}

\section{Bed rest in singleton pregnancies for preventing preterm birth}

\author{
Claudio G Sosa ${ }^{1}$, Fernando Althabe ${ }^{2}$, José M Belizán ${ }^{2}$, Eduardo Bergel ${ }^{3}$ \\ ${ }^{1}$ Department of Obstetrics and Gynecology - School of Medicine, University of Uruguay, Montevideo, Uruguay. ${ }^{2}$ Department of \\ Mother and Child Health Research, Institute for Clinical Effectiveness and Health Policy (IECS), Buenos Aires, Argentina. ${ }^{3}$ Department \\ of Biostatistics, Institute for Clinical Effectiveness and Health Policy (IECS), Buenos Aires, Argentina \\ Contact address: Claudio G Sosa, Department of Obstetrics and Gynecology - School of Medicine, University of Uruguay, Echevarriarza \\ 3320 Apartment 701, Montevideo, 11300, Uruguay. sosaclau@gmail.com. csosa@tulane.edu.
}

Editorial group: Cochrane Pregnancy and Childbirth Group.

Publication status and date: New search for studies and content updated (no change to conclusions), published in Issue 3, 2015.

Review content assessed as up-to-date: 18 December 2014.

Citation: Sosa CG, Althabe F, Belizán JM, Bergel E. Bed rest in singleton pregnancies for preventing preterm birth. Cochrane Database of Systematic Reviews 2015, Issue 3. Art. No.: CD003581. DOI: 10.1002/14651858.CD003581.pub3.

Copyright (C) 2015 The Cochrane Collaboration. Published by John Wiley \& Sons, Ltd.

\begin{abstract}
A B S T R A C T
Background

Bed rest in hospital or at home is widely recommended for the prevention of preterm birth. This advice is based on the observation that hard work and hard physical activity during pregnancy could be associated with preterm birth and with the idea that bed rest could reduce uterine activity. However, bed rest may have some adverse effects on other outcomes.
\end{abstract}

\section{Objectives}

To evaluate the effect of prescription of bed rest in hospital or at home for preventing preterm birth in pregnant women at high risk of preterm birth.

\section{Search methods}

We searched the Cochrane Pregnancy and Childbirth Group's Trials Register (18 December 2014), the Cochrane Central Register of Controlled Trials (The Cochrane Library, 2014, Issue 12), MEDLINE (December 2014), EMBASE (December 2014), LILACS (December 2014), and bibliographies of relevant papers.

\section{Selection criteria}

Randomized, cluster-randomized and quasi-randomized controlled trials with reported data that assess clinical outcomes in women at high risk of spontaneous preterm birth who were prescribed bed rest in hospital or at home for preventing preterm birth, and their babies.

\section{Data collection and analysis}

Two review authors independently assessed eligibility, trial quality and extracted data.

\section{Main results}

Two studies met the inclusion criteria. One study was not considered for the meta-analysis, since data combined singleton and multiple pregnancies. No differences in any maternal and perinatal outcomes were reported by the authors. This study was at low risk of selection, performance, detection and attrition bias. Only data from one study were included in the meta-analysis (1266 women). This study was at unclear risk of bias for most domains due to lack of reporting. Four hundred and thirty-two women were prescribed bed rest at home and a total of 834 women received a placebo (412) or no intervention (422). Preterm birth before 37 weeks was similar in both

Bed rest in singleton pregnancies for preventing preterm birth (Review)

Copyright $\odot 2015$ The Cochrane Collaboration. Published by John Wiley \& Sons, Ltd. 
groups $(7.9 \%$ in the intervention group versus $8.5 \%$ in the control group; risk ratio (RR) $0.92,95 \%$ confidence interval (CI) 0.62 to 1.37). No other results were reported for any of the other primary or secondary outcomes.

\section{Authors' conclusions}

There is no evidence, either supporting or refuting the use of bed rest at home or in hospital, to prevent preterm birth. Although bed rest in hospital or at home is widely used as the first step of treatment, there is no evidence that this practice could be beneficial. Due to the potential adverse effects that bed rest could have on women and their families, and the increased costs for the healthcare system, clinicians should discuss the pros and cons of bed rest to prevent preterm birth. Potential benefits and harms should be discussed with women facing an increased risk of preterm birth. Appropriate research is mandatory. Future trials should evaluate both the effectiveness of bed rest, and the effectiveness of the prescription of bed rest, to prevent preterm birth.

\section{PLAIN LANGUAGE SUMMARY}

\section{Bed rest in singleton pregnancies for preventing preterm birth}

No evidence to support or refute bed rest in preventing preterm birth.

Although bed rest in hospital or at home is widely used as the first step of treatment, this updated review finds no evidence to support or refute bed rest in preventing preterm birth. The current practice has been based on observational studies that found an association between hard work or hard physical activity and preterm birth. Due to the potential adverse effects that bed rest could have on women and their families, and the increased costs for the healthcare system, the pros and cons of bed rest for preventing preterm birth should be discussed fully.

Bed rest in singleton pregnancies for preventing preterm birth (Review)

Copyright $\odot 2015$ The Cochrane Collaboration. Published by John Wiley \& Sons, Ltd. 